\title{
Optimal cut-off values of BMI, waist circumference and waist:height ratio for defining obesity in Chinese adults
}

\author{
Qiang Zeng ${ }^{1 *}+$, Yuan $\mathrm{He}^{2} \dagger$, Shengyong Dong ${ }^{1}$, Xiaolan Zhao ${ }^{3 *}$, Zhiheng Chen $^{4}$, Zhenya Song ${ }^{5}$, \\ Guang Chang ${ }^{6}$, Fang Yang ${ }^{7}$ and Youjuan Wang 8 \\ ${ }^{1}$ International Medical Center, Chinese People's Liberation Army General Hospital, 28 Fuxing Road, Beijing 100083, \\ People's Republic of China \\ ${ }^{2}$ National Research Institute for Family Planning, Beijing 100081, People's Republic of China \\ ${ }^{3}$ Southwest Hospital, Third Military Medical University, Chongqing 400038, People's Republic of China \\ ${ }^{4}$ Third Xiangya Hospital, Central South University, Changsha 410013, People's Republic of China \\ ${ }^{5}$ The Second Affiliated Hospital, Medical College of Zhejiang University, Hangzhou 310009, People's Republic of China \\ ${ }^{6}$ Bethune International Peace Hospital, Shijiazhuang 050082, People's Republic of China \\ ${ }^{7}$ The First Hospital of Jilin University, Changchun 130021, People's Republic of China \\ ${ }^{8}$ West China Hospital of Sichuan University, Chengdu 610041, People's Republic of China
}

(Submitted 2 March 2014 - Final revision received 1 July 2014 - Accepted 31 July 2014 - First published online 10 October 2014)

\begin{abstract}
It has not been established which specific measures of obesity might be most appropriate for predicting CVD risk in Asians. The objectives of the present study were to determine the associations of BMI, waist circumference (WC) and waist:height ratio (WHtR) with CVD risk factors and to evaluate the optimal cut-off values to define overweight or obesity in Chinese adults. Data collected from seven nationwide health examination centres during 2008 and 2009 were analysed. The BMI, WC and WHtR of 244266 Chinese adults aged $\geq 20$ years included in the study were measured. Logistic regression models were fit to evaluate the OR of each CVD risk factor according to various anthropometric indices. Receiver operating characteristic (ROC) analyses were conducted to assess the optimal cut-off values to predict the risk of diabetes, hypertension, dyslipidaemia and the metabolic syndrome. WHtR had the largest areas under the ROC curve for all CVD risk factors in both sexes, followed by WC and BMI. The optimal cut-off values were approximately 24.0 and $23.0 \mathrm{~kg} / \mathrm{m}^{2}$ for BMI, 85.0 and $75.0 \mathrm{~cm}$ for WC, and 0.50 and 0.48 for WHtR for men and women, respectively. According to well-established cut-off values, BMI was found to be a more sensitive indicator of hypertension in both men and women, while WC and WHtR were found to be better indicators of diabetes and dyslipidaemia. A combination of BMI and central obesity measures was found to be associated with greater OR of CVD risk factors than either of them alone in both sexes. The present study demonstrated that WHtR and WC may be better indicators of CVD risk factors for Chinese people than BMI.
\end{abstract}

Key words: Obesity: CVD: Waist:height ratio: Risk factors

The prevalence of obesity is increasing among Chinese urban adults due to rapid economic development and lifestyle changes in China ${ }^{(1-3)}$. In a national survey carried out from 2000 to 2001, Reynolds et al. ${ }^{(1)}$ reported high overweight and obesity prevalence rates of 52.5 and $13 \cdot 1 \%$, respectively, for men and 48.4 and $12 \cdot 8 \%$, respectively, for women in urban regions. Obesity significantly elevates the risk of CVD, diabetes, insulin resistance and other metabolic disorders ${ }^{(4,5)}$. BMI is a widely used anthropometric index for measuring body fatness in clinical practice and epidemiological studies; additionally, BMI is independently associated with CVD risk factors $^{(6,7)}$. However, indices of central obesity, such as waist circumference (WC) and waist:height ratio (WHtR), are suggested to be better indicators of cardiometabolic risk because they reflect body fat distribution and upper body adiposity $^{(8-10)}$. Because WC does not account for differences in height, WHtR has been considered a superior predictor than BMI and WC for discriminating CVD risk factors ${ }^{(11-13)}$

Asians are more likely to have a higher percentage of body fat at lower BMI and WC than Europeans, which may lead to

\footnotetext{
Abbreviations: AUROC, area under the receiver operating characteristic curve; MetS, metabolic syndrome; ROC, receiver operating characteristic; WC, waist circumference; WGOC, Working Group on Obesity in China; WHtR, waist:height ratio.
}

*Corresponding authors: Q. Zeng, fax +86 10 68295928, email zq301@126.com; X. Zhao, fax +86 23 68754919, email 1021211982@qq.com

† These authors contributed equally to the study. 
the greater prevalence of CVD risk factors at a relatively lower BMI in Asian populations ${ }^{(14-16)}$. The WHO suggests that the cut-off values for public health action for Asians are BMI values $\geq 23 \mathrm{~kg} / \mathrm{m}^{2}$ to represent an increased risk of CVD and BMI values $\geq 27.5 \mathrm{~kg} / \mathrm{m}^{2}$ to represent a high risk of $\mathrm{CVD}^{(15)}$. The International Diabetes Federation has proposed ethnicity-specific WC cut-off points as a prerequisite component of the metabolic syndrome (MetS), with the values ranging from 80 to $90 \mathrm{~cm}$ in Asians ${ }^{(17)}$. In response to the recommendations, the Working Group on Obesity in China (WGOC) has suggested that a BMI in excess of $24 \mathrm{~kg} / \mathrm{m}^{2}$ or a WC exceeding $85 \mathrm{~cm}$ in men and $80 \mathrm{~cm}$ in women signifies overweight or central obesity in the general Chinese population, according to thirteen population studies conducted in the $1990 \mathrm{~s}^{(18)}$. However, evidence regarding whether different cut-off values are appropriate in Chinese is insufficient ${ }^{(3)}$. On the other hand, several studies have attempted to determine the optimal cut-off values for WHtR to predict various CVD risk factors based on data from either small-scale or cross-sectional studies, mostly conducted in Taiwan and Hong Kong ${ }^{(19-21)}$. Most of the available data indicate that a cut-off WHtR value is needed for the general population in Mainland China ${ }^{(22-24)}$. Thus, the present population-based study aimed to determine the associations between three anthropometric indices (BMI, WC and $\mathrm{WH} \mathrm{H}$ ) and common CVD risk factors, including diabetes, hypertension, dyslipidaemia and the MetS; it also aimed to evaluate the optimal cut-off values of these anthropometric indices for urban Chinese adults.

\section{Subjects and methods}

\section{Subjects}

A large population-based cross-sectional study was carried out in seven nationwide health examination centres between 2008 and 2009. A two-stage cluster random-sampling design was used to determine the risk factors of chronic diseases among Chinese urban adults. In the first stage of sampling, the process was stratified by north $v$. south, as divided by the Yangtze River. According to economic development and geographical regions, three cities (Beijing, Shijiazhuang and Changchun) from northern China and four cities (Chongqing, Changsha, Hangzhou and Chengdu) from southern China were selected. In the second stage of sampling, one local representative health check-up centre was randomly selected from each city. All individuals who visited the health check-up centre were then selected for the present study. A total of 244266 examinees aged $\geq 20$ years were found to be eligible for the study. Among these, 16798 subjects without relevant data on demography, blood pressure, and glucose and lipid concentrations, 5780 subjects with a history of cancer that might affect the measurements of anthropometric factors, and 418 subjects who were pregnant or lactating at the time of examination were excluded. The remaining subjects comprised 137256 men (mean age 45.61 (SD 14.28) years) and 84014 women (mean age 43.79 (SD 13.58) years). The present study was conducted according to the guidelines laid down in the Declaration of Helsinki and was approved by the Ethics Committee of the Chinese People's Liberation Army General Hospital and the Chinese
Society of Health Management. Written informed consent was obtained from all subjects.

\section{Measurements}

Anthropometric measurements were conducted in subjects in barefoot and light clothing. Height, WC (measured to the nearest $0.1 \mathrm{~cm}$ ) and weight (measured to the nearest $0.1 \mathrm{~kg}$ ) were measured by trained personnel using standardised techniques and equipments. WC was measured midway between the inferior margin of the last rib and the crest of the ileum in a horizontal plane. BMI was calculated as weight $(\mathrm{kg})$ divided by height squared $\left(\mathrm{m}^{2}\right)$. WHtR was calculated as WC $(\mathrm{cm})$ divided by height $(\mathrm{cm})$. After $10 \mathrm{~min}$ of rest while seated, the same staff measured systolic blood pressure and diastolic blood pressure in the right arm using an appropriate electronic sphygmomanometer. A venous blood sample was collected in the morning after a fast of at least $8 \mathrm{~h}$; this blood sample was used for measuring plasma glucose, TAG, total cholesterol and HDL-cholesterol concentrations in the clinical laboratory of the People's Liberation Army General Hospital. LDL-cholesterol was quantified using the Friedewald formula:

$$
\begin{aligned}
\text { LDL-cholesterol }(\mathrm{mmol} / \mathrm{l}) & =\text { total cholesterol } \\
& -\left(\frac{\text { HDL-cholesterol }+ \text { TAG }}{2 \cdot 2}\right) .
\end{aligned}
$$

\section{Definitions}

Diabetes was defined as either having fasting plasma glucose concentrations $\geq 7.0 \mathrm{mmol} / 1$ or physician-diagnosed diabetes. Hypertension was defined as having systolic blood pressure $\geq 140 \mathrm{mmHg}$ and/or diastolic blood pressure $\geq 90 \mathrm{mmHg}$ or as physician-diagnosed hypertension. Dyslipidaemia was defined as having plasma total cholesterol concentrations $\geq 6.22 \mathrm{mmol} / 1$ and/or fasting TAG concentrations $\geq 2.26 \mathrm{mmol} / 1$ and/or LDL-cholesterol concentrations $\geq 4.14 \mathrm{mmol} / 1$ and/or HDLcholesterol concentrations $<1.04 \mathrm{mmol} / \mathrm{l}^{(25)}$. The MetS was defined as the presence of at least two of the following: plasma TAG concentrations $>1.70 \mathrm{mmol} / \mathrm{l}$; HDL-cholesterol concentrations $<1.04 \mathrm{mmol} / \mathrm{l}$; blood pressure $>130 / 85 \mathrm{mmHg}$; fasting plasma glucose concentrations $>5.6 \mathrm{mmol} / \mathrm{l} ; 2 \mathrm{~h}$ oral glucose tolerance test plasma glucose concentrations $>7.8 \mathrm{mmol} / \mathrm{l}$, which are similar to those used in recently published studies ${ }^{(23)}$.

\section{Statistical analyses}

All variables are expressed as means and standard deviations or percentages where appropriate. Groups were compared using Student's $t$ test for continuous variables and the $\chi^{2}$ test for categorical variables. Receiver operating characteristic (ROC) analyses were carried out to compare predictive ability and to calculate optimal cut-off values for each anthropometric parameter and risk condition. The area under the ROC curve (AUROC) is a measure of the diagnostic power of a test. An AUROC of 1 indicates a perfect prediction and an AUROC of 0.5 indicates the absence of predictive power. Optimal cut-off values were defined as the points on the ROC curve where 
Table 1. Characteristics of the study population

(Mean values and standard deviations; number of participants and percentages)

\begin{tabular}{|c|c|c|c|c|c|c|c|c|c|c|c|c|c|c|}
\hline & \multicolumn{14}{|c|}{ Age groups } \\
\hline & \multicolumn{2}{|l|}{$20-$} & \multicolumn{2}{|c|}{$30-$} & \multicolumn{2}{|c|}{$40-$} & \multicolumn{2}{|c|}{$50-$} & \multicolumn{2}{|c|}{$60-$} & \multicolumn{2}{|c|}{$70-$} & \multicolumn{2}{|l|}{ Total } \\
\hline & Mean & SD & Mean & SD & Mean & SD & Mean & SD & Mean & SD & Mean & SD & Mean & SD \\
\hline $\operatorname{Men}(n)$ & 17825 & & 34585 & & 36693 & & 24207 & & 13223 & & 10623 & & 137256 & \\
\hline Height $(\mathrm{cm})$ & $171 \cdot 7^{\star \star \star}$ & 6.0 & $170 \cdot 2^{\star \star \star}$ & 5.9 & $169 \cdot 5^{\star \star \star}$ & 5.9 & $168 \cdot 7^{\star \star \star}$ & $6 \cdot 2$ & $166 \cdot 5^{\star \star \star}$ & $6 \cdot 2$ & $165 \cdot 3^{\star \star \star}$ & 6.1 & $169 \cdot 2^{\star \star *}$ & $6 \cdot 3$ \\
\hline Weight (kg) & $69 \cdot 1^{\star \star \star}$ & 11.6 & $71 \cdot 1^{\star \star \star}$ & 10.5 & $72 \cdot 2^{\star \star \star}$ & $10 \cdot 1$ & $71 \cdot 7^{\star \star \star}$ & 9.9 & $69 \cdot 1^{\star \star \star}$ & 9.8 & $66 \cdot 3^{\star \star \star}$ & $10 \cdot 2$ & $70 \cdot 7^{\star \star \star}$ & $10 \cdot 5$ \\
\hline $\mathrm{BMI}\left(\mathrm{kg} / \mathrm{m}^{2}\right)$ & $23 \cdot 4^{\star \star \star}$ & 3.5 & $24 \cdot 5^{\star \star \star}$ & 3.2 & $25 \cdot 1^{\star \star \star}$ & 3.0 & $25 \cdot 1^{\star \star \star}$ & 2.9 & $24 \cdot 8^{\star \star \star}$ & 3.0 & $24 \cdot 2$ & 3.2 & $24 \cdot 6^{\star \star \star}$ & 3.1 \\
\hline$W C(\mathrm{~cm})$ & $80 \cdot 4^{\star \star \star}$ & 9.4 & $84.4^{\star \star \star}$ & $8 . \overline{5}$ & $86 \cdot 8^{\star \star \star}$ & 8.3 & $87 \cdot 3^{\star \star \star}$ & 8.4 & $86 \cdot 7^{\star \star \star}$ & 8.6 & $86 \cdot 1^{\star \star \star}$ & $9 . \overline{6}$ & $85 \cdot 4^{\star \star \star}$ & 8.9 \\
\hline WHtR & $0.47^{\star \star \star}$ & 0.05 & $0.50^{*}$ & 0.05 & $0.51^{\star \star}$ & 0.05 & $0.52^{\star \star}$ & 0.05 & 0.52 & 0.05 & $0.52^{*}$ & 0.06 & $0.50^{\star \star \star}$ & 0.05 \\
\hline $\mathrm{FBG}(\mathrm{mmol} / \mathrm{l})$ & $4 \cdot 9^{\star \star \star}$ & 0.6 & $5 \cdot 1^{\star \star \star}$ & 0.9 & $5 \cdot 3^{\star \star \star}$ & $1 \cdot 3$ & $5 \cdot 6^{\star \star \star}$ & 1.6 & $5 \cdot 7^{\star \star \star}$ & 1.8 & $5 \cdot 8^{\star \star \star}$ & 1.5 & $5 \cdot 4^{\star \star \star}$ & 1.3 \\
\hline $\mathrm{SBP}(\mathrm{mmHg})$ & $119 \cdot 0^{\star \star \star}$ & 12.9 & $119 \cdot 4^{\star \star \star}$ & 14.1 & $122 \cdot 4^{\star \star \star}$ & 16.4 & $127 \cdot 3^{\star \star \star}$ & 17.8 & 134.7 & $19 \cdot 2$ & $140 \cdot 1$ & 19.4 & $124 \cdot 6^{* \star *}$ & 17.5 \\
\hline DBP $(\mathrm{mmHg})$ & $74 \cdot 0^{\star \star \star}$ & $9 \cdot 3$ & $76 \cdot 6^{\star \star \star}$ & $11 \cdot 2$ & $80 \cdot 3^{\star \star *}$ & $13 \cdot 3$ & $82 \cdot 2^{\star \star \star}$ & $14 \cdot 0$ & $82 \cdot 1^{\star \star \star}$ & 14.4 & $78 \cdot 9^{\star \star \star}$ & $15 \cdot 6$ & $78 \cdot 9^{\star \star *}$ & $13 \cdot 1$ \\
\hline $\mathrm{TC}(\mathrm{mmol} / \mathrm{l})$ & $3 \cdot 7^{\star \star \star}$ & 1.5 & $4 \cdot 0^{\star \star \star}$ & 1.7 & $4 \cdot 3^{\star \star \star}$ & 1.7 & $4 \cdot 3$ & 1.6 & $4 \cdot 0^{\star \star \star}$ & 1.7 & $3 \cdot 9^{\star \star \star}$ & 1.7 & $4 \cdot 1^{\star \star \star}$ & 1.7 \\
\hline TAG (mmol/l) & $2 \cdot 0^{* \star \star}$ & 1.6 & $2 \cdot 6^{\star \star \star}$ & 1.9 & $2 \cdot 8^{\star \star \star}$ & 2.0 & $2 \cdot 6^{\star \star \star \star}$ & 1.9 & $2 \cdot 5^{\star \star \star}$ & 1.8 & $2 \cdot 4^{\star \star \star}$ & 1.7 & $2 \cdot 5^{\star \star \star}$ & 1.9 \\
\hline $\mathrm{HDL}-\mathrm{C}(\mathrm{mmol} / \mathrm{l})$ & $1 \cdot 3^{\star \star \star}$ & 0.3 & $1 \cdot 2^{\star \star \star}$ & 0.3 & $1 \cdot 2^{\star \star \star}$ & 0.4 & $1 \cdot 3^{\star \star \star}$ & 0.3 & $1 \cdot 3^{\star \star \star}$ & 0.4 & $1 \cdot 3^{* \star *}$ & 0.4 & $1 \cdot 3^{\star \star \star}$ & 0.3 \\
\hline \multirow{2}{*}{\multicolumn{15}{|c|}{ Diabetes }} \\
\hline & & & & & & & & & & & & & & \\
\hline$n$ & \multirow{2}{*}{\multicolumn{2}{|c|}{$\begin{array}{c}180^{\star * *} \\
1.0\end{array}$}} & \multicolumn{2}{|c|}{$924^{\star * *}$} & 261 & & \multicolumn{2}{|c|}{$2899^{\star \star \star}$} & \multicolumn{2}{|c|}{$1944^{\star \star \star}$} & 17 & & \multicolumn{2}{|l|}{$10260^{\star \star *}$} \\
\hline$\%$ & & & 2 & & 7. & & 12 & & 14 & & 16 & & 7.5 & \\
\hline \multicolumn{15}{|l|}{ Hypertension } \\
\hline$n$ & \multirow{2}{*}{\multicolumn{2}{|c|}{$\begin{array}{c}1439^{\star \star \star} \\
8.0\end{array}$}} & 470 & & 951 & & 930 & & 6744 & & 66 & & $38391^{* \star \star}$ & \\
\hline$\%$ & & & 13 & & 25 & & 38 & & 51 & & 62 & & 28.0 & \\
\hline Dyslipidaemia & & & & & & & & & & & & & & \\
\hline$n$ & $7323^{\star \star}$ & & 188 & & 2181 & & 1354 & & 717 & & 529 & & $74038^{\star \star \star \star}$ & \\
\hline $\begin{array}{c}\% \\
\text { MetS }\end{array}$ & 40.9 & & 5 & & 59 & & 56 & & 54 & & 45 & & 53.9 & \\
\hline$n$ & $3893^{\star \star}$ & & & & & & & & & & & & & \\
\hline$\%$ & $\begin{array}{r}21.7 \\
21.7\end{array}$ & & $\begin{array}{r}123 \\
35\end{array}$ & & $\begin{array}{r}1 / 54 \\
47\end{array}$ & & $\begin{array}{r}1296 \\
53\end{array}$ & & $\begin{array}{r}7632 \\
57\end{array}$ & & $\begin{array}{r}649 \\
61\end{array}$ & & $\begin{array}{c}60826^{* * \star} \\
44 \cdot 3\end{array}$ & \\
\hline Women $(n)$ & 13531 & & 22272 & & 22444 & & 14057 & & 7237 & & 4473 & & 84014 & \\
\hline Height $(\mathrm{cm})$ & $160 \cdot 0$ & 5.4 & 158.9 & 5.4 & 158.5 & 5.4 & $157 \cdot 2$ & 5.6 & 154.5 & 5.5 & 152.4 & $5 \cdot 7$ & 158.0 & 5.8 \\
\hline Weight (kg) & $52 \cdot 3$ & $7 \cdot 2$ & 54.5 & $7 \cdot 3$ & $57 \cdot 2$ & 7.8 & 58.9 & 8.4 & 58.4 & 8.7 & $56 \cdot 3$ & 9.5 & $56 \cdot 0$ & $8 \cdot 2$ \\
\hline BMI $\left(\mathrm{kg} / \mathrm{m}^{2}\right)$ & 20.4 & 2.5 & 21.6 & $2 \cdot 6$ & 22.8 & 2.8 & 23.8 & 3.0 & 24.5 & 3.3 & 24.2 & 3.6 & 22.5 & $3 \cdot 1$ \\
\hline WC $(\mathrm{cm})$ & 68.6 & 6.8 & 71.4 & 6.7 & 74.2 & $7 \cdot 3$ & 77.8 & 7.9 & 80.5 & 8.7 & 81.5 & $9 \cdot 6$ & 74.1 & 8.4 \\
\hline WHtR & 0.43 & 0.04 & 0.45 & 0.04 & 0.47 & 0.05 & 0.50 & 0.05 & 0.52 & 0.06 & 0.54 & 0.06 & 0.47 & 0.06 \\
\hline $\mathrm{FBG}(\mathrm{mmol} / \mathrm{l})$ & 4.8 & 0.5 & 4.9 & 0.6 & 5.0 & 0.8 & 5.3 & 1.2 & 5.6 & 1.4 & $5 \cdot 7$ & 1.4 & 5.1 & 0.9 \\
\hline SBP $(\mathrm{mmHg})$ & $106 \cdot 2$ & $10 \cdot 8$ & 107.4 & $12 \cdot 0$ & $113 \cdot 3$ & 15.4 & 123.8 & $18 \cdot 5$ & 134.2 & $19 \cdot 7$ & $140 \cdot 4$ & $20 \cdot 1$ & $115 \cdot 6$ & $18 \cdot 4$ \\
\hline $\mathrm{DBP}(\mathrm{mmHg})$ & 68.3 & 9.9 & 69.2 & 9.2 & 72.6 & 11.5 & 76.7 & 11.3 & 78.3 & 11.1 & 76.6 & 11.6 & 72.4 & 11.2 \\
\hline $\mathrm{TC}(\mathrm{mmol} / \mathrm{l})$ & 3.4 & 1.5 & 3.5 & 1.6 & 3.8 & 1.7 & 4.3 & 1.9 & 4.4 & 1.9 & 4.5 & 1.9 & 3.8 & $1 . \overline{7}$ \\
\hline TAG $(\mathrm{mmol} / \mathrm{l})$ & 1.6 & 1.5 & 1.8 & 1.6 & $2 \cdot 0$ & 1.7 & 2.4 & 1.9 & $2 \cdot 7$ & 1.9 & 2.6 & 1.8 & 2.0 & 1.7 \\
\hline $\mathrm{HDL}-\mathrm{C}(\mathrm{mmol} / \mathrm{l})$ & 1.6 & 0.3 & 1.5 & 0.3 & 1.5 & 0.4 & 1.5 & 0.4 & 1.5 & 0.4 & 1.5 & 0.4 & 1.5 & 0.4 \\
\hline LDL-C $(\mathrm{mmol} / \mathrm{l})$ & 2.5 & 0.6 & 2.3 & 0.6 & 2.5 & 0.7 & 3.0 & 0.8 & 3.1 & 0.9 & 3.1 & 0.8 & $2 \cdot 6$ & 0.8 \\
\hline Diabetes & & & & & & & & & & & & & & \\
\hline$n$ & 78 & & & & 62 & & 89 & & 83 & & 6 & & 3340 & \\
\hline$\%$ & 0.6 & & 1 & & 2 & & 6 & & 11 & & 14 & & $4 \cdot 0$ & \\
\hline Hypertension & & & & & & & & & & & & & & \\
\hline$n$ & 121 & & 6 & & 22 & & 388 & & 345 & & 28 & & 13188 & \\
\hline$\%$ & 0.9 & & 2 & & 10 & & 27 & & 47 & & 63 & & $15 \cdot 7$ & \\
\hline Dyslipidaemia & & & & & & & & & & & & & & \\
\hline & 3655 & & 69 & & 77 & & 64 & & 380 & & 23 & & 30901 & \\
\hline$\%$ & $27 \cdot 0$ & & 3 & & 34 & & 45 & & 52 & & 53 & & $36 \cdot 8$ & \\
\hline MetS & & & & & & & & & & & & & & \\
\hline$n$ & 1226 & & 32 & & 55 & & 598 & & 437 & & 29 & & 23327 & \\
\hline$\%$ & $9 \cdot 1$ & & 14 & & 24 & & 42 & & 60 & & 66 & & 27.8 & \\
\hline
\end{tabular}

WC, waist circumference; WHtR, waist:height ratio; FBG, fasting blood glucose; SBP, systolic blood pressure; DBP, diastolic blood pressure; TC, total cholesterol; HDL-C, HDL-cholesterol; LDL-C, LDL-cholesterol; MetS, metabolic syndrome.

Mean value was significantly different from that of women within an age group: ${ }^{*} P<0.05,{ }^{* \star *} P<0.001$. 
Youden's index (sensitivity + specificity -1 ) was the highest. Differences between two AUROC were tested with $Z$ values: $Z=\frac{\left(A_{\mathrm{A}}-A_{\mathrm{B}}\right)}{\sqrt{\left(S_{\mathrm{EA}}^{2}+S_{\mathrm{EB}}^{2}\right)}}$, with $Z>1 \cdot 96, P<0 \cdot 05$, and with $Z>2 \cdot 58$ $P<0 \cdot 01$. OR were calculated by applying logistic regression models. Statistical inference was based on $95 \%$ CI and $5 \%$ $P$ values, respectively. All statistical analyses involved the use of SPSS version 19.0 (IBM, Inc.).

\section{Results}

The characteristics of the study population according to sex and 10-year age groups are given in Table 1 . Men aged 20-69 years had higher BMI values than women, while men and women aged $\geq 70$ years had similar BMI values. Men and women of a similar age were more likely to have higher WC values in all age groups; men aged 50-59 years also had higher WHtR values. Significant age-related differences were also observed: all anthropometric measures tended to reach the highest level by the late $50 \mathrm{~s}$ in men, while they gradually increased with age in women. In addition, men were more likely to have higher fasting glucose concentrations, higher blood pressure values and more adverse lipid profiles when compared with women. The percentage of men with diabetes, hypertension, dyslipidaemia and the MetS was significantly higher than that of women in each age group. Dyslipidaemia and the MetS were more prevalent in men than in women. The prevalence of all risk factors increased substantially with an increase in age in both sexes, except for a slight drop in the risk of dyslipidaemia in men aged $\geq 60$ years.
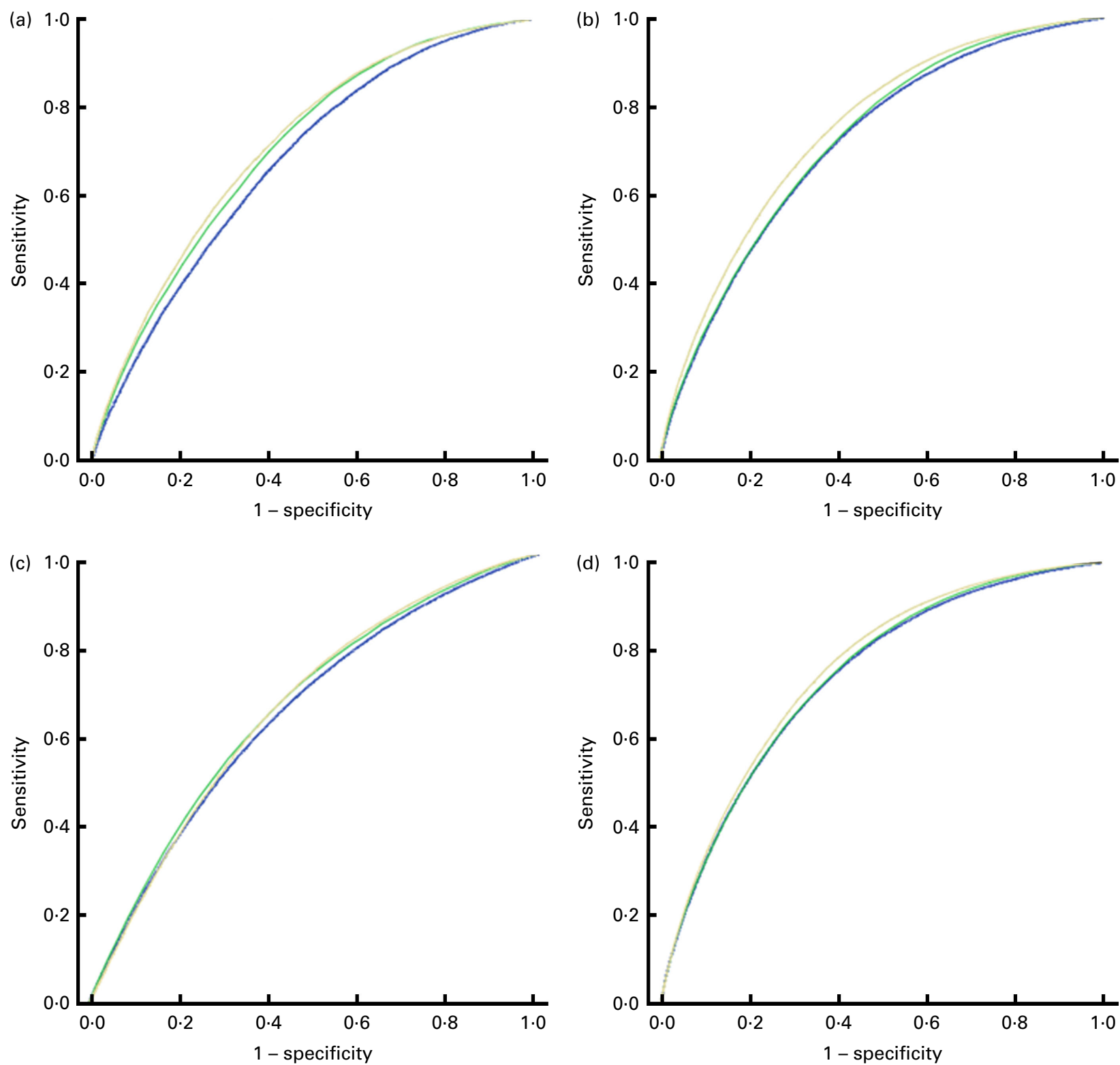

Fig. 1. Receiver operating characteristic curves for BMI (-), waist circumference $(-)$ and waist:height ratio $(-)$ in relation to (a) diabetes, (b) hypertension, (c) dyslipidaemia and (d) the metabolic syndrome. Areas for the curves in men and women are summarised in Table 2. (A colour version of this figure can be found online at http://www.journals.cambridge.org/bjn). 
ROC curves are shown in Fig. 1. The OR and AUROC for BMI, WC and WHtR in relation to CVD risk factors are given in Table 2. Expressed per $1 \mathrm{SD}$ increment in anthropometric indices, WHtR corresponded to significantly higher OR for hypertension, dyslipidaemia and the MetS in men, while WC corresponded to higher OR for all CVD risk factors in men when compared with other indices in women. The AUROC for BMI ranged between 0.626 and $0.708 \mathrm{~kg} / \mathrm{m}^{2}$ for men and between 0.599 and $0.765 \mathrm{~kg} / \mathrm{m}^{2}$ for women. The AUROC for WC ranged between 0.642 and $0.711 \mathrm{~cm}$ for men and between 0.615 and $0.775 \mathrm{~cm}$ for women. The AUROC for WHtR ranged between 0.645 and 0.721 for men and between 0.626 and 0.773 for women. Generally speaking, WHtR had the largest AUROC for all risk factors in both sexes, followed by WC and BMI $(P<0 \cdot 05)$. Although WC had larger AUROC than BMI for dyslipidaemia in men, there were no significant differences in the AUROC for WC and BMI $(P>0.05)$. WHtR and WC also performed similarly well for diabetes in women $(P>0.05)$. The AUROC for diabetes, hypertension and the MetS were larger in women than in men, but the AUROC for dyslipidaemia were larger in men than in women $(P<0.05)$.

The AUROC for various anthropometric indices stratified by 10-year age groups are summarised in Table S1 (available online). In men, the AUROC for CVD risk factors were larger in the younger age groups than in the older age groups. In women, all indices had better discriminatory power for selected metabolic conditions in the middle age groups. WC or WHtR had the largest AUROC for diabetes and dyslipidaemia in both sexes, while BMI had apparently larger AUROC for hypertension. Although BMI had larger AUROC for the MetS in the older age groups of men, there were no significant differences in AUROC for BMI, WC and WHtR in women.

The optimal cut-off values of anthropometric indices determined using the ROC analyses in both sexes are summarised in Tables 3 and 4. In men, the BMI cut-off values that were found to optimally predict the risk of diabetes, hypertension, dyslipidaemia and the MetS ranged from $24 \cdot 2$ to $24 \cdot 3 \mathrm{~kg} / \mathrm{m}^{2}$. The optimal WC cut-off values ranged from 83.8 to $86.3 \mathrm{~cm}$ and the optimal WHtR cut-off values varied from 0.50 to 0.51. In women, the optimal BMI cut-off values ranged from 22.4 to $23.3 \mathrm{~kg} / \mathrm{m}^{2}$ and the optimal WC cut-off values varied from 73.8 to $77.8 \mathrm{~cm}$. The optimal WHtR cut-off values ranged from 0.47 to 0.49 . In addition, the optimal cut-off values of BMI, WC and WHtR were mostly higher for men than for women in each age group, and the differences between sexes decreased with an increase in age (see online supplementary Tables S2 and S3). Men in the middle age groups had higher cut-off values than those in other age groups, while women in younger age groups tended to have lower cut-off values. The optimal cut-off values of BMI and WC varied greatly by sex, age and CVD risk factors, while the optimal cut-off values of WHtR had an upper limit of 0.50 that could be applied in the majority of age groups in both sexes.

Using the cut-off values of BMI and WC recommended by the WGOC as well as the cut-off value of WHtR determined

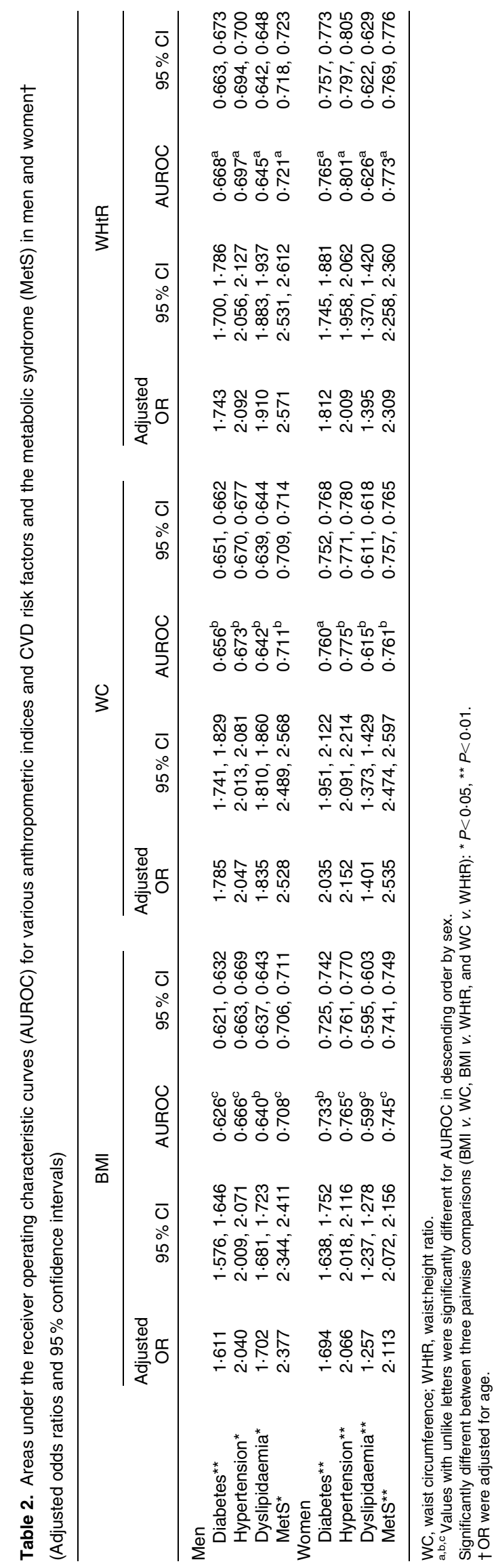


N British Journal of Nutrition

Table 3. Cut-off values of BMI, waist circumference (WC) and waist:height ratio (WHtR) that are predictive of CVD risk factors in men

\begin{tabular}{|c|c|c|c|c|c|c|c|c|c|c|c|c|}
\hline & \multicolumn{4}{|c|}{ BMI } & \multicolumn{4}{|c|}{ WC } & \multicolumn{4}{|c|}{ WHtR } \\
\hline & $\begin{array}{c}\text { Cut-off } \\
\text { values }\left(\mathrm{kg} / \mathrm{m}^{2}\right)\end{array}$ & $\begin{array}{c}\text { Sensitivity } \\
(\%)\end{array}$ & $\begin{array}{c}\text { Specificity } \\
(\%)\end{array}$ & $\begin{array}{c}\text { Correctly } \\
\text { classified }(\%)\end{array}$ & $\begin{array}{c}\text { Cut-off } \\
\text { values }(\mathrm{cm})\end{array}$ & $\begin{array}{c}\text { Sensitivity } \\
(\%)\end{array}$ & $\begin{array}{c}\text { Specificity } \\
(\%)\end{array}$ & $\begin{array}{c}\text { Correctly } \\
\text { classified (\%) }\end{array}$ & $\begin{array}{l}\text { Cut-off } \\
\text { values }\end{array}$ & $\begin{array}{c}\text { Sensitivity } \\
(\%)\end{array}$ & $\begin{array}{c}\text { Specificity } \\
(\%)\end{array}$ & $\begin{array}{c}\text { Correctly } \\
\text { classified (\%) }\end{array}$ \\
\hline \multicolumn{13}{|l|}{ Diabetes } \\
\hline Optimal & $24 \cdot 2$ & $72 \cdot 3$ & 45.6 & 47.7 & $86 \cdot 3$ & $65 \cdot 6$ & $56 \cdot 2$ & 56.9 & 0.51 & 67.4 & $56 \cdot 6$ & $56 \cdot 2$ \\
\hline China $1^{*}$ & 24.0 & 74.2 & $43 \cdot 2$ & 45.5 & $85 \cdot 0$ & 74.8 & 46.7 & 48.8 & - & - & - & - \\
\hline China $2^{*}$ & 28.0 & $23 \cdot 3$ & 87.2 & 82.4 & - & - & - & - & - & - & - & - \\
\hline WHO† & $30 \cdot 0$ & 9.4 & 95.8 & $89 \cdot 3$ & $102 \cdot 0$ & $8 \cdot 8$ & 97.0 & 90.4 & 0.50 & $77 \cdot 0$ & $46 \cdot 0$ & 48.3 \\
\hline \multicolumn{13}{|c|}{ Hypertension } \\
\hline Optimal & $24 \cdot 3$ & 70.7 & $53 \cdot 2$ & 57.8 & $85 \cdot 3$ & 68.1 & 56.9 & 60.1 & 0.51 & 65.4 & $63 \cdot 3$ & $63 \cdot 0$ \\
\hline China $1^{*}$ & $24 \cdot 0$ & $75 \cdot 0$ & 48.4 & 55.9 & $85 \cdot 0$ & $72 \cdot 6$ & $52 \cdot 0$ & 57.8 & - & - & - & - \\
\hline China $2^{*}$ & 28.0 & 23.4 & 90.2 & 71.5 & - & - & - & - & - & - & - & - \\
\hline WHOt & 30.0 & 9.1 & 97.1 & 72.5 & $102 \cdot 0$ & $7 \cdot 2$ & 98.0 & $72 \cdot 6$ & 0.50 & $75 \cdot 8$ & $52 \cdot 1$ & $58 \cdot 7$ \\
\hline \multicolumn{13}{|c|}{ Dyslipidaemia } \\
\hline Optimal & $24 \cdot 2$ & 64.6 & $56 \cdot 3$ & 60.7 & 83.8 & $69 \cdot 3$ & $52 \cdot 0$ & $61 \cdot 3$ & 0.50 & 68.5 & 53.7 & $61 \cdot 3$ \\
\hline China $1^{\star}$ & 24.0 & 67.6 & 53.0 & 60.9 & 85.0 & 64.5 & 56.4 & 60.8 & - & - & - & - \\
\hline China $2^{\star}$ & 28.0 & 17.6 & 91.0 & 51.4 & - & - & - & - & - & - & - & - \\
\hline WHO† & $30 \cdot 0$ & $6 \cdot 2$ & $97 \cdot 2$ & $48 \cdot 1$ & $102 \cdot 0$ & 4.5 & 97.8 & 47.5 & 0.50 & 65.7 & $56 \cdot 0$ & 61.3 \\
\hline \multicolumn{13}{|l|}{ MetS } \\
\hline Optimal & $24 \cdot 2$ & $72 \cdot 0$ & 58.6 & 64.4 & 84.8 & $72 \cdot 1$ & 58.8 & 64.7 & 0.50 & $71 \cdot 7$ & $60 \cdot 7$ & $65 \cdot 3$ \\
\hline China $1^{*}$ & 24.0 & 74.9 & $55 \cdot 3$ & 64.0 & 85.0 & $72 \cdot 1$ & 58.8 & 64.7 & - & - & - & - \\
\hline China $2^{\star}$ & $28 \cdot 0$ & $21 \cdot 8$ & 92.9 & $61 \cdot 4$ & - & - & - & - & - & - & - & - \\
\hline WHOt & 30.0 & 8.1 & 98.1 & 58.2 & $102 \cdot 0$ & $6 \cdot 1$ & 98.6 & 57.6 & 0.50 & 73.7 & 58.7 & $65 \cdot 3$ \\
\hline
\end{tabular}

MetS, metabolic syndrome

"Proposed overweight and obesity criteria according to the Working Group on Obesity in China.

tObesity criteria for Caucasians according to the WHO.

Table 4. Cut-off values of BMI, waist circumference (WC) and waist:height ratio (WHtR) that are predictive of CVD risk factors in women

\begin{tabular}{|c|c|c|c|c|c|c|c|c|c|c|c|c|}
\hline & \multicolumn{4}{|c|}{ BMI } & \multicolumn{4}{|c|}{ wC } & \multicolumn{4}{|c|}{ WHtR } \\
\hline & $\begin{array}{c}\text { Cut-off } \\
\text { values }\left(\mathrm{kg} / \mathrm{m}^{2}\right)\end{array}$ & $\begin{array}{c}\text { Sensitivity } \\
(\%)\end{array}$ & Specificity (\%) & $\begin{array}{c}\text { Correctly } \\
\text { classified (\%) }\end{array}$ & $\begin{array}{c}\text { Cut-off } \\
\text { values }(\mathrm{cm})\end{array}$ & $\begin{array}{c}\text { Sensitivity } \\
(\%)\end{array}$ & $\begin{array}{c}\text { Specificity } \\
(\%)\end{array}$ & $\begin{array}{c}\text { Correctly } \\
\text { classified }(\%)\end{array}$ & $\begin{array}{l}\text { Cut-off } \\
\text { values }\end{array}$ & $\begin{array}{c}\text { Sensitivity } \\
(\%)\end{array}$ & $\begin{array}{c}\text { Specificity } \\
(\%)\end{array}$ & $\begin{array}{c}\text { Correctly } \\
\text { classified (\%) }\end{array}$ \\
\hline \multicolumn{13}{|l|}{ Diabetes } \\
\hline Optimal & 23.3 & 68.0 & $67 \cdot 2$ & 66.6 & $77 \cdot 8$ & 68.5 & $70 \cdot 8$ & $70 \cdot 7$ & 0.49 & $69 \cdot 3$ & 71.8 & $69 \cdot 4$ \\
\hline China $1^{*}$ & 24.0 & 60.1 & 73.6 & 73.1 & 80.0 & 61.1 & $77 \cdot 3$ & 76.6 & - & - & - & - \\
\hline China $2^{\star}$ & 28.0 & 19.9 & 95.0 & 92.0 & - & - & - & - & - & - & - & - \\
\hline \multirow{2}{*}{\multicolumn{13}{|c|}{ Hypertension }} \\
\hline & & & & & & & & & & & & \\
\hline Optimal & $23 \cdot 3$ & 69.5 & $71 \cdot 3$ & $71 \cdot 1$ & 76.8 & 69.9 & $71 \cdot 8$ & 71.5 & 0.49 & $73 \cdot 3$ & 73.0 & 74.3 \\
\hline China $1^{*}$ & 24.0 & 60.2 & 78.3 & 75.5 & 80.0 & 57.1 & 81.8 & 78.0 & - & - & - & - \\
\hline China $2^{*}$ & 28.0 & 18.0 & 96.7 & 84.4 & - & - & - & - & - & - & - & - \\
\hline WHOt & 30.0 & 8.0 & 98.9 & 84.6 & 88.0 & 22.5 & 95.9 & 84.4 & 0.50 & $65 \cdot 1$ & 79.7 & $77 \cdot 4$ \\
\hline \multicolumn{13}{|c|}{ Dyslipidaemia } \\
\hline Optimal & 22.4 & 55.0 & 59.8 & 58.0 & 73.8 & 59.0 & 58.2 & 58.5 & 0.47 & $59 \cdot 7$ & 58.8 & 59.9 \\
\hline China $1^{\star}$ & 24.0 & 35.4 & 76.8 & 61.6 & 80.0 & 32.2 & 80.4 & 62.7 & - & - & - & - \\
\hline China $2^{*}$ & 28.0 & 7.7 & 95.6 & 63.3 & - & - & - & - & - & - & - & - \\
\hline WHOt & 30.0 & 3.0 & 98.3 & 63.2 & 88.0 & 9.6 & 94.6 & $63 \cdot 3$ & 0.50 & 36.5 & 78.0 & 62.7 \\
\hline \multicolumn{13}{|l|}{ MetS } \\
\hline Optimal & 22.9 & $65 \cdot 8$ & 71.3 & $69 \cdot 7$ & $75 \cdot 8$ & $71 \cdot 6$ & $67 \cdot 7$ & 75.4 & 0.48 & 67.9 & 73.5 & 71.8 \\
\hline China $1^{\star}$ & 24.0 & 52.0 & 81.6 & 73.4 & 80.0 & 48.4 & 85.0 & 74.8 & - & - & - & - \\
\hline China $2^{*}$ & 28.0 & 13.8 & 97.6 & 74.2 & - & - & - & - & - & - & - & - \\
\hline WHOt & 30.0 & 5.7 & 99.2 & 73.2 & 88.0 & $17 \cdot 0$ & 96.9 & 74.7 & 0.50 & $54 \cdot 3$ & 83.0 & 75.0 \\
\hline
\end{tabular}

MetS, metabolic syndrome.

* Proposed overweight and obesity criteria according to the Working Group on Obesity in China.

† Obesity criteria for Caucasians according to the WHO. 
Table 5. Various anthropometric indices and CVD risk factors in men and women* $\dagger$ (Adjusted odds ratios and $95 \%$ confidence intervals)

\begin{tabular}{|c|c|c|c|c|c|c|}
\hline & \multicolumn{2}{|c|}{$\mathrm{BMI} \geq 24$ v. $<24 \mathrm{~kg} / \mathrm{m}^{2}$} & \multicolumn{2}{|c|}{$\begin{array}{c}W C \geq 85 \mathrm{v} .<85 \mathrm{~cm} \text { (men) or } \\
W C \geq 80 \mathrm{v} .<80 \mathrm{~cm} \\
\text { (women) }\end{array}$} & \multicolumn{2}{|c|}{ WHtR $\geq 0.5 v .<0.5$} \\
\hline & Adjusted OR & $95 \% \mathrm{Cl}$ & Adjusted OR & $95 \% \mathrm{Cl}$ & Adjusted OR & $95 \% \mathrm{Cl}$ \\
\hline \multicolumn{7}{|l|}{ Men } \\
\hline Diabetes & $2 \cdot 12$ & $2 \cdot 02,2 \cdot 22$ & $2 \cdot 30$ & $2 \cdot 19,2 \cdot 41$ & $2 \cdot 26$ & $2 \cdot 16,2 \cdot 37$ \\
\hline Hypertension & 2.96 & $2 \cdot 88,3.05$ & $2 \cdot 65$ & $2 \cdot 58,2 \cdot 72$ & $2 \cdot 75$ & $2 \cdot 68,2 \cdot 83$ \\
\hline Dyslipidaemia & $2 \cdot 34$ & $2 \cdot 29,2 \cdot 39$ & $2 \cdot 36$ & $2 \cdot 30,2 \cdot 41$ & $2 \cdot 48$ & $2.43,2.54$ \\
\hline MetS & 3.64 & $3.55,3.73$ & 3.42 & $3.34,3.50$ & 3.50 & $3.41,3.58$ \\
\hline \multicolumn{7}{|l|}{ Women } \\
\hline Diabetes & $2 \cdot 51$ & $2 \cdot 33,2.70$ & 2.92 & $2 \cdot 71,3 \cdot 16$ & $2 \cdot 86$ & $2 \cdot 64,3 \cdot 10$ \\
\hline Hypertension & $3 \cdot 16$ & $3.02,3.30$ & $2 \cdot 83$ & $2 \cdot 70,2 \cdot 96$ & 2.92 & $2.79,3.06$ \\
\hline Dyslipidaemia & 1.46 & $1.41,1.51$ & 1.52 & $1.47,1.58$ & 1.56 & $1.51,1.62$ \\
\hline MetS & $3 \cdot 17$ & $3.06,3 \cdot 28$ & $3 \cdot 21$ & $3 \cdot 10,3 \cdot 33$ & $3 \cdot 28$ & $3 \cdot 16,3.40$ \\
\hline
\end{tabular}

WC, waist circumference; $\mathrm{WH}$ R, waist:height ratio; MetS, metabolic syndrome.

${ }^{*}$ All $P$ values for the adjusted odd ratios were $<0.001$.

†OR were adjusted for age.

in the present study, all these obesity indices were found to have a greater than 2-fold increased risk for CVD risk factors, except for dyslipidaemia in women (Table 5). WC and WHtR were superior to BMI in their association with diabetes and dyslipidaemia, whereas BMI was better able to predict the risk of hypertension in both sexes. When compared with other indices, a higher BMI for men and a higher WHtR for women usually had the highest risk predictive power for the MetS. The combined effects of BMI, WC and WHtR are summarised in Table 6. Men and women with a BMI $\geq 24.0 \mathrm{~kg} / \mathrm{m}^{2}$ and a WC $\geq 85$ (in men) or $\geq 80 \mathrm{~cm}$ (in women) had a significantly increased risk than those with a BMI $<24.0 \mathrm{~kg} / \mathrm{m}^{2}$ and a WC $<85$ (in men) or $<80 \mathrm{~cm}$ (in women). Similar results were also obtained for subjects with a BMI $\geq 24.0 \mathrm{~kg} / \mathrm{m}^{2}$ and a WHtR $\geq 0.5$ in both sexes, suggesting that simultaneous use of both parameters could much improve the predictive power. Higher indices of central obesity were associated with a greater risk of diabetes and dyslipidaemia in normal-weight subjects (BMI $<24.0 \mathrm{~kg} / \mathrm{m}^{2}$ ). However, a higher BMI without a concomitantly higher WC or WHtR was associated with a moderate increased risk for the development of hypertension and the MetS.

\section{Discussion}

The present study, carried out using data obtained from more than 220000 urban adults from Mainland China, showed that WHtR and WC performed better than BMI as a central measure of obesity for discriminating CVD risk factors. The optimal cut-off values for men and women were approximately $24 \cdot 0$ and $23.0 \mathrm{~kg} / \mathrm{m}^{2}$ for BMI, 85.0 and $75.0 \mathrm{~cm}$ for $\mathrm{WC}$, and 0.50 and 0.48 for WHtR, respectively. It also supports the idea that the combination of BMI and central obesity measures, corresponding to the well-established cut-off values, identifies a particularly greater CVD risk than either of them alone in both sexes.

WHtR has been found to have a stronger association with multiple CVD risk factors in several studies conducted in China ${ }^{(19-21)}$, Korea ${ }^{(11)}$, Japan ${ }^{(26)}$ and other ethnic $\operatorname{groups}^{(27,28)}$. Among the three anthropometric indices, WHtR had the largest AUROC for all CVD risk factors, except for diabetes in women. When the relative risk for a 1-unit change in standard deviation was calculated after controlling for age, WHtR was found to have a stronger association with hypertension, dyslipidaemia and the MetS in men, while WC was found to be a better predictor for all CVD risk factors in women. Thus, our data support the superiority of WHtR and WC over BMI for detecting CVD risk factors in both men and women.

The public health message derived from the data on WHtR is simple: keep your WC to less than half your height ${ }^{(29)}$. Optimal cut-off values that fell within the same narrow range of $0.48-0.52$ in both sexes were reported by one study carried out in Taiwan ${ }^{(19)}$. Ho et al. ${ }^{(20)}$ recommended an optimal cut-off value of 0.48 for Hong Kong Chinese individuals of both sexes, and He et al. ${ }^{(22)}$ defined an optimal cut-off value of 0.50 for predicting the risk of diabetes in both sexes in the Chinese population. Furthermore, Lin $e t a l .{ }^{(21)}$ reported that a WHtR of 0.48 for men and that of 0.45 for women may be the appropriate cut-off values using health examination data. In addition, several meta-analyses on CVD outcomes carried out on data obtained from Caucasian, Asian and Central American populations in prospective and cross-sectional studies have suggested that a WHtR cut-off value of 0.5 could be applied to different sexes and age groups ${ }^{(27,28,30)}$.

A number of studies have shown that Asians have a higher percentage of body fat than Caucasian at lower BMI and $\mathrm{WC}^{(14,31)}$. The current definitions of overweight and central obesity are based on Western populations and probably need to be modified for the Chinese population. The WGOC has recently developed the cut-off values for overweight $\left(24.0 \mathrm{~kg} / \mathrm{m}^{2}\right)$ using BMI and central obesity $(85.0 \mathrm{~cm}$ for men and $80.0 \mathrm{~cm}$ for women) and WC for the general Chinese population ${ }^{(18)}$. In the present study, the optimal cut-off values for urban Chinese male and female adults were found to be 24.0 and $23.0 \mathrm{~kg} / \mathrm{m}^{2}$ for BMI and 85.0 and $75.0 \mathrm{~cm}$ for WC, respectively. Compared with WGOC definitions, these values were very similar in men, but apparently 
lower in women. Previous studies have indicated that the cutoff values for observed risk varied from 24 to $26 \mathrm{~kg} / \mathrm{m}^{2}$ for BMI and from 85 to $87 \mathrm{~cm}$ for WC in Taiwanese men and from 22 to $23 \mathrm{~kg} / \mathrm{m}^{2}$ for BMI and from 74 to $83 \mathrm{~cm}$ for WC in Taiwanese women; similar to the present study population, this study also enrolled subjects from health examination centres $^{(19)}$. Studies in other Asian countries have also reported a BMI cut-off value of $22-24 \mathrm{~kg} / \mathrm{m}^{2}$ for men and women and WC cut-off values of about $80-85 \mathrm{~cm}$ for men and $75-80 \mathrm{~cm}$ for women ${ }^{(32-34)}$. Similar to these results, our data suggested that the cut-off points for Chinese urban women might be lower than the criteria suggested by the WGOC, but our data were in agreement with the cut-off values reported for Asian populations with a higher economic status.

Under the current WGOC recommendations, BMI is a more sensitive indicator of hypertension in men and women, while WHtR and WC are better indicators of diabetes and dyslipidaemia. This is agreement with the results of the ROC curve analyses carried out in the present study after stratification by age groups. Dong et $a l .{ }^{(23)}$ reported that BMI is more strongly associated with hypertension than WC and WHtR in Chinese men. Another previous study carried out in 29079 Chinese adults has suggested that the best indicator of hypertension is WHtR in men and BMI in women ${ }^{(35)}$. However, Park et $a l .{ }^{(11)}$ analysed the OR of each obesity index according to the quartiles and found that WC and WHtR are superior to BMI for predicting the risk of hypertension and other CVD risk factors. The direct comparison between obesity indices based on the OR value becomes less convincing unless a standard unit increment for each measurement is clearly defined and widely accepted. Further studies should assess the association between overall/central obesity and hypertension using different methods. In addition, previous studies have suggested that the combination of BMI and WC has a better predictive power for CVD risk factors than either measure alone ${ }^{(36,37)}$. The results of the present study support the conclusion that those with both BMI and WC values above the cut-off values have a greater risk of diabetes, hypertension, dyslipidaemia and the MetS in both sexes. Similar results were also obtained when BMI and WHtR were used together. In the present study, $12.2 \%$ of normal-weight people had higher WC values $(\geq 85 \mathrm{~cm}$ for men or $\geq 80 \mathrm{~cm}$ for women), while $13.3 \%$ had higher WHtR values $(\geq 0.5$ for men and women). This indicates that some non-obese people may already have a central fat distribution with a higher CVD risk than when BMI cut-off values are used alone. These findings suggest that the combined measures of BMI and indices of central obesity are effective for identifying individuals at a higher risk.

The present study investigated the associations between obesity indicators and CVD risk factors in a large population of Mainland China. There are still no clear cut-off values for obesity indices in Asians. The present study used a very large sample covering most age groups to estimate optimal cut-off values to predict CVD risk factors. These data are appropriate for defining cut-off values of BMI, WC and WHtR in Chinese populations. In addition, the high quality of the anthropometric measurements and laboratory data 
reduced the potential biases and measurement errors. A major limitation of the present study is its cross-sectional design, which cannot be used to establish temporal relationship and causality. Further longitudinal studies are needed to determine these associations. Second, the results should be interpreted with caution because data were collected from individuals who came for health check-ups. Although these individuals were generally more concerned about their health than non-participants, it is unlikely to cause a bias in determining the actual associations between obesity indices and CVD risk factors. Furthermore, data on potential confounders such as smoking and other lifestyles were not collected, which represents another limitation.

In conclusion, the present study showed that WHtR and WC may be better than BMI for discriminating CVD risk factors. Our data suggest that the cut-off values for BMI and WC to define obesity should be much lower in China than in Western countries. Moreover, a global WHtR cut-off value of 0.50 may also be the appropriate upper limit for Chinese urban adults.

\section{Supplementary material}

To view supplementary material for this article, please visit http://dx.doi.org/10.1017/S0007114514002657

\section{Acknowledgements}

The present study was supported by the State Science and Technology Support Program (grant no. 2012BAI37B04) and the Military Eleventh Five Year Health Promotion Program (grant no. 10BJZ18).

The authors' contributions are as follows: Q. Z. and Y. H. designed the study; Y. H. analysed the data and wrote the manuscript; Y. H. and S. D. collected and assembled the data; Q. Z., X. Z., Z. C., Z. S., G. C., F. Y. and Y. W. interpreted the data, provided advice or consultation, and approved the final manuscript; Q. Z. obtained funding.

None of the authors has any conflicts of interest to declare.

\section{References}

1. Reynolds K, Gu D, Whelton PK, et al. (2007) Prevalence and risk factors of overweight and obesity in China. Obesity (Silver Spring) 15, 10-18.

2. Wildman RP, Gu D, Muntner P, et al. (2008) Trends in overweight and obesity in Chinese adults: between 1991 and 1999-2000. Obesity (Silver Spring) 16, 1448-1453.

3. Meguid El Nahas A \& Bello AK (2005) Chronic kidney disease: the global challenge. Lancet 365, 331-340.

4. Zalesin KC, Franklin BA, Miller WM, et al. (2011) Impact of obesity on cardiovascular disease. Med Clin North Am 95 , 919-937.

5. Nordmann AJ, Nordmann A, Briel M, et al. (2006) Effects of low-carbohydrate $v s$ low-fat diets on weight loss and cardiovascular risk factors: a meta-analysis of randomized controlled trials. Arch Intern Med 166, 285-293.

6. Berrington de Gonzalez A, Hartge P, Cerhan JR, et al. (2010) Body-mass index and mortality among 1.46 million white adults. $N$ Engl J Med 363, 2211-2219.
7. Deurenberg P, Yap M \& van Staveren WA (1998) Body mass index and percent body fat: a meta analysis among different ethnic groups. Int J Obes Relat Metab Disord 22, 1164-1171.

8. Zhu S, Wang Z, Heshka S, et al. (2002) Waist circumference and obesity-associated risk factors among whites in the third National Health and Nutrition Examination Survey: clinical action thresholds. Am J Clin Nutr 76, 743-749.

9. Zhu S, Heymsfield SB, Toyoshima H, et al. (2005) Raceethnicity-specific waist circumference cutoffs for identifying cardiovascular disease risk factors. Am J Clin Nutr 81, 409-415.

10. Ashwell M, Lejeune S \& McPherson K (1996) Ratio of waist circumference to height may be better indicator of need for weight management. BMJ 312, 377.

11. Park SH, Choi SJ, Lee KS, et al. (2009) Waist circumference and waist-to-height ratio as predictors of cardiovascular disease risk in Korean adults. Circ J 73, 1643-1650.

12. Aekplakorn W, Pakpeankitwatana V, Lee CM, et al. (2007) Abdominal obesity and coronary heart disease in Thai men. Obesity (Silver Spring) 15, 1036-1042.

13. Hsieh SD \& Muto T (2005) The superiority of waist-to-height ratio as an anthropometric index to evaluate clustering of coronary risk factors among non-obese men and women. Prev Med 40, 216-220.

14. Deurenberg P, Deurenberg-Yap M \& Guricci S (2002) Asians are different from Caucasians and from each other in their body mass index/body fat per cent relationship. Obes Rev 3, 141-146.

15. WHO Expert Consultation (2004) Appropriate body-mass index for Asian populations and its implications for policy and intervention strategies. Lancet 363, 157-163.

16. Chen YM, Ho SC, Lam SS, et al. (2006) Validity of body mass index and waist circumference in the classification of obesity as compared to percent body fat in Chinese middle-aged women. Int J Obes (Lond) 30, 918-925.

17. Zimmet P, Magliano D, Matsuzawa Y, et al. (2005) The metabolic syndrome: a global public health problem and a new definition. $J$ Atheroscler Thromb 12, 295-300.

18. Bei-Fan Z (2002) Cooperative Meta-Analysis Group of Working Group on Obesity in China Predictive values of body mass index and waist circumference for risk factors of certain related diseases in Chinese adults: study on optimal cut-off points of body mass index and waist circumference in Chinese adults. Asia Pac J Clin Nutr 11, S685-S693.

19. Tseng CH, Chong CK, Chan TT, et al. (2010) Optimal anthropometric factor cutoffs for hyperglycemia, hypertension and dyslipidemia for the Taiwanese population. Atherosclerosis 210, 585-589.

20. Ho SY, Lam TH \& Janus ED (2003) Waist to stature ratio is more strongly associated with cardiovascular risk factors than other simple anthropometric indices. Ann Epidemiol 13, 683-691.

21. Lin WY, Lee LT, Chen CY, et al. (2002) Optimal cut-off values for obesity: using simple anthropometric indices to predict cardiovascular risk factors in Taiwan. Int $J$ Obes Relat Metab Disord 26, 1232-1238.

22. He Y, Zhai F, Ma G, et al. (2009) Abdominal obesity and the prevalence of diabetes and intermediate hyperglycaemia in Chinese adults. Public Health Nutr 12, 1078-1084.

23. Dong X, Liu Y, Yang J, et al. (2011) Efficiency of anthropometric indicators of obesity for identifying cardiovascular risk factors in a Chinese population. Postgrad Med J 87, 251-256.

24. Liu Y, Tong G, Tong W, et al. (2011) Can body mass index, waist circumference, waist-hip ratio and waist-height ratio predict the presence of multiple metabolic risk factors in Chinese subjects? BMC Public Health 11, 35. 
25. Joint Committee for Developing Chinese Guidelines on Prevention and Treatment of Dyslipidemia in Adults (2007) Chinese guidelines on prevention and treatment of dyslipidemia in adults. Zhonghua Xin Xue Guan Bing Za Zhi 35, 390-419.

26. Hsieh SD, Yoshinaga H \& Muto T (2003) Waist-to-height ratio, a simple and practical index for assessing central fat distribution and metabolic risk in Japanese men and women. Int J Obes Relat Metab Disord 27, 610-616.

27. Lee CM, Huxley RR, Wildman RP, et al. (2008) Indices of abdominal obesity are better discriminators of cardiovascular risk factors than BMI: a meta-analysis. J Clin Epidemiol 61, 646-653.

28. Ashwell M, Gunn P \& Gibson S (2012) Waist-to-height ratio is a better screening tool than waist circumference and BMI for adult cardiometabolic risk factors: systematic review and meta-analysis. Obes Rev 13, 275-286.

29. Ashwell M \& Hsieh SD (2005) Six reasons why the waistto-height ratio is a rapid and effective global indicator for health risks of obesity and how its use could simplify the international public health message on obesity. Int J Food Sci Nutr 56, 303-307.

30. Browning LM, Hsieh SD \& Ashwell M (2010) A systematic review of waist-to-height ratio as a screening tool for the prediction of cardiovascular disease and diabetes: 0.5 could be a suitable global boundary value. Nutr Res Rev 23, 247-269.
31. Deurenberg-Yap M, Chew SK \& Deurenberg P (2002) Elevated body fat percentage and cardiovascular risks at low body mass index levels among Singaporean Chinese, Malays and Indians. Obes Rev 3, 209-215.

32. Pua YH \& Ong PH (2005) Anthropometric indices as screening tools for cardiovascular risk factors in Singaporean women. Asia Pac J Clin Nutr 14, 74-79.

33. Ito H, Nakasuga K, Ohshima A, et al. (2003) Detection of cardiovascular risk factors by indices of obesity obtained from anthropometry and dual-energy X-ray absorptiometry in Japanese individuals. Int J Obes Relat Metab Disord 27, $232-237$.

34. Moon OR, Kim NS, Jang SM, et al. (2002) The relationship between body mass index and the prevalence of obesityrelated diseases based on the 1995 National Health Interview Survey in Korea. Obes Rev 3, 191-196.

35. Zhou Z, Hu D \& Chen J (2009) Association between obesity indices and blood pressure or hypertension: which index is the best? Public Health Nutr 12, 1061-1071.

36. Zhu S, Heshka S, Wang Z, et al. (2004) Combination of BMI and waist circumference for identifying cardiovascular risk factors in whites. Obes Res 12, 633-645.

37. Du SM, Ma GS, Li YP, et al. (2010) Relationship of body mass index, waist circumference and cardiovascular risk factors in Chinese adult. Biomed Environ Sci 23, 92-101. 